\title{
Tip Apex Distance: a useful method to assess extra-capsular neck of femur fixation?
}

\section{Davies J*, Mokawem M and Guy S}

Department of Trauma and Orthopaedics, Bradford Teaching Hospitals NHS Foundation Trust, The Cottage, Gate 2, Bradford Royal Infirmary, Duckworth Lane, Bradford, BD9 6RJ, UK

\begin{abstract}
Introduction: Fixation of trochanteric femoral neck fractures can be problematic. The tip apex distance (TAD) is a simple measurement that predicts screw cut-out in the femoral head from fractures treated with a fixed angle sliding hip screw device. By assessing whether the measurements in our centre were comparable to published results, we wanted to assess our proficiency in fixing these injuries as well as the general usefulness of this measurement in day to day practice.
\end{abstract}

Methods: A retrospective review was conducted of 102 consecutively treated trochanteric fractures over a 12 month period, with 11 patients excluded. Three observers $(n=3)$ used a standardised method to measure the TAD (from 2 orthogonal projections with a correction for magnification). The stability of the fracture patterns with the accuracy of reduction were measured according to published criteria.

Results: 91 fractures were sustained in 90 patients, with one patient being treated for bilateral hip fractures. The mean tip apex distance was $19.06 \mathrm{~mm} \pm 0.77 \mathrm{~mm}( \pm 95 \% \mathrm{Cl})$. Assessing the inter-observer variability, the standard deviation between the 3 observers was $1.99 \mathrm{~mm}$, equivalent to $10 \%$ of the mean TAD. 12 out of 91 sliding hip screw devices $(13.1 \%)$ had a TAD greater then $25 \mathrm{~mm}$, predictive of a higher extrusion rate.

Conclusions: Measurement of the TAD can provide a reliable method to examine the adequacy of screw placement in the femoral head. Our results compare favourably to those published and we have found a similar level of inter-observer variability, confirming the usefulness of this measurement in assessing the quality of fixation and its reproducibility. By determining which patients have an increased risk of failure of fixation by screw cut-out we have been able to offer targeted surveillance rather than routinely following up all patients: bringing back those with a high TAD for $x$-ray follow up.

Keywords: Tip apex distance; Hip fracture

\section{Introduction}

The Tip Apex Distance (TAD) is a simple measurement that predicts screw cut-out in the femoral head from trochanteric fractures treated with a fixed angle sliding hip screw device [1]. It uses a numerical value to show placement of the screw in the head: higher values indicating higher likelihood of fixation failure by extrusion of the screw. Currently the cost of hip fracture care in the UK is great, at an estimated $£ 1.4$ billion per annum [2]. In order to examine the care delivered to these 70,000 patients affected by a neck of femur fracture, The National Hip Fracture Database (NHFD) collects information about case-mix, care and patient outcomes. However, actual data pertaining to the adequacy of fixation for fracture treatment is not routinely audited. Analysis of NHFD data according to fracture subtypes has shown that for the UK population: $41 \%$ were displaced intracapsular, $13 \%$ undisplaced intracapsular, 35\% intertrochanteric and 6\% subtrochanteric fractures [2]. Intertrochanteric fractures therefore comprise a significant proportion of the fractures sustained in the population. Nationally, the majority ( $81 \%)$ were treated by a sliding hip screw device [2].

To assess the adequacy of fixation in our centre of these fractures, we determined whether TAD measurements were comparable to previously published results, how reproducible these measurements were between observers and how accurate we were at reducing the fractures. The commonest mode of failure of sliding hip screw devices is cut-out, or extrusion, from the femoral head [3-6]. Position of the lag screw as determined by the TAD has been shown the most important predictive factor in cut-out and this radiographic measurement can be readily determined using published methods $[1,3]$. In many UK centres, routine follow up in hip fracture patients after fixation does not occur except for intracapsular fractures treated by internal fixation, in whom there is a risk of non-union (20-33\%) and avascular necrosis (10-20\%) necessitating re-operation [7]. Patients with a sliding hip screw device with a lag screw that has a high TAD have a higher risk of cut-out, and they should similarly be considered for follow-up for $\mathrm{x}$-ray surveillance.

\section{Methods}

A retrospective review was conducted of 102 consecutively treated trochanteric fractures over a 12 month period. This data was extracted from the existing database of all hip fractures, submitted for audit to the NHFD. 11 patients were excluded because they did not sustain a trochanteric fracture (2), had treatment of a pathological fracture (3) or because of incomplete radiographic data (6). Three observers used a standardised method to measure the TAD, which was defined as the sum of the distance in $\mathrm{mm}$, from the tip of the lag screw to the apex of

*Corresponding author: John Davies, Department of Trauma and Orthopaedics, Bradford Teaching Hospitals NHS Foundation Trust, 12 Newton Garth, Leeds, LS7 4JZ, Bradford, UK, Tel. +44-7918025495; E-mail: johnfdavies@hotmail.com

Received March 03, 2012; Accepted March 13, 2012; Published March 15, 2012

Citation: Davies J, Mokawem M, Guy S (2012) Tip Apex Distance: a useful method to assess extra-capsular neck of femur fixation? J Trauma Treatment 1:119. doi:10.4172/2167-1222.1000119

Copyright: (C) 2012 Davies J, et al. This is an open-access article distributed unde the terms of the Creative Commons Attribution License, which permits unrestricted use, distribution, and reproduction in any medium, provided the original author and source are credited. 
the femoral head on anteroposterior (AP) and lateral projections, with a correction for magnification by multiplying with a factor derived from the diameter of the lag screw, Figure 1. The apex of the femoral head is defined as the point of intersection between the subchondral bone and a line in the centre of and parallel to the femoral neck [1]. The stability of the fracture patterns was assessed according to the Evans criteria modified by Kyle and AO [8]. The accuracy of reduction was measured according to criteria from the original Baumgaertner paper, Table 1 [1].

\section{Results}

91 fractures were sustained in 90 patients, with one patient being treated for bilateral hip fractures. The majority of patients were female, the male to female ratio being 33:57. The mean age of the patients at the time of treatment was 80 years (range 18 to 101). Four different implants were used during the study period: 63 Dynamic Hip Screws (DHS), 26 Gamma Nails (GN), 1 Proximal Femoral Nail (PFN) and 1 Intramedullary Hip Screw (IMHS). Ten fractures (11\%) were classified as unstable, Figure 2, and $88(96.7 \%)$ had a good or acceptable reduction in theatre. The mean tip apex distance was $19.06 \mathrm{~mm} \pm 0.77$ $\mathrm{mm}( \pm 95 \% \mathrm{CI})$, Figure 3 . There was 1 screw cut-out through the femoral head during the data collection period in a patient with an unstable fracture. Assessing the inter-observer variability, the standard deviation between the 3 observers was $1.99 \mathrm{~mm}$, equivalent to $10 \%$ of the mean TAD. Twelve sliding hip screw devices (13.1\%) had a TAD greater then $25 \mathrm{~mm}$, predictive of a much higher extrusion rate.

\section{Discussion}

Sliding hip screw devices have an associated re-operation rate for implant failure which is associated with increased morbidity for patients $[9,10]$. Studies have shown that there are predictive factors for lag screw cut-out, the most important relating to the position of the lag screw in the femoral head as determined by the TAD, in addition to other factors including the degree of comminution of the fracture site and quality of reduction $[1,3,11,12]$. The current practice in many centres is for no formal follow-up of patients following discharge from

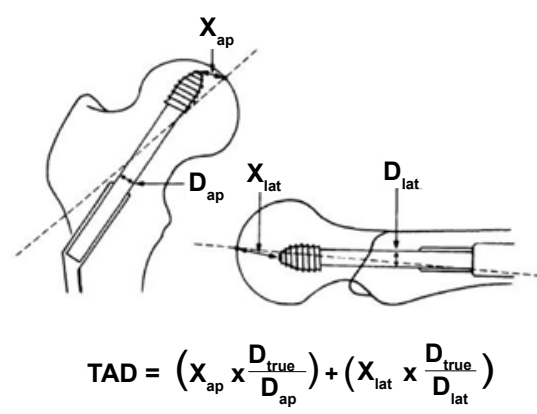

Figure 1: Technique for calculating the Tip Apex Distance. TAD is the sum of the distance in $\mathrm{mm}$ from the apex of the femoral head to the tip of the lag screw with correction for magnification in AP and lateral views. Reproduced from Baumgartner et al. [1]

\begin{tabular}{|l|l|}
\hline Reduction & $\begin{array}{l}\text { Normal or slight angulation on AP view and }<20^{\circ} \text { angulation on } \\
\text { lateral view. }\end{array}$ \\
\hline Displacement & $\leq 4 \mathrm{~mm}$ displacement of any fragment \\
\hline
\end{tabular}

For a "good" reduction: both criteria were necessary; "acceptable", either but not both were met, for a "poor" reduction neither criteria were met. Reproduced from Baumgartner et al. [1].

Table 1: Criterion for accuracy of reduction.

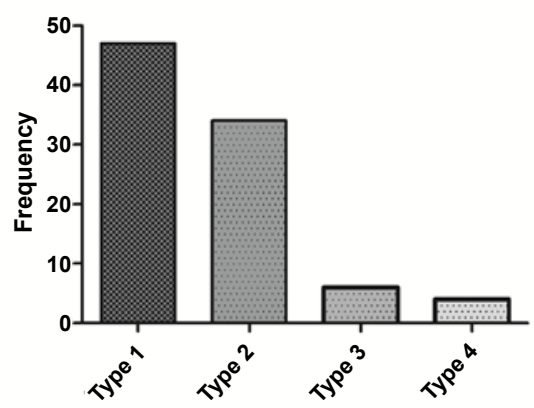

Figure 2: Fracture stability by Evans Kyle classification (Types 1-2, stable; 3-4, unstable) [8].

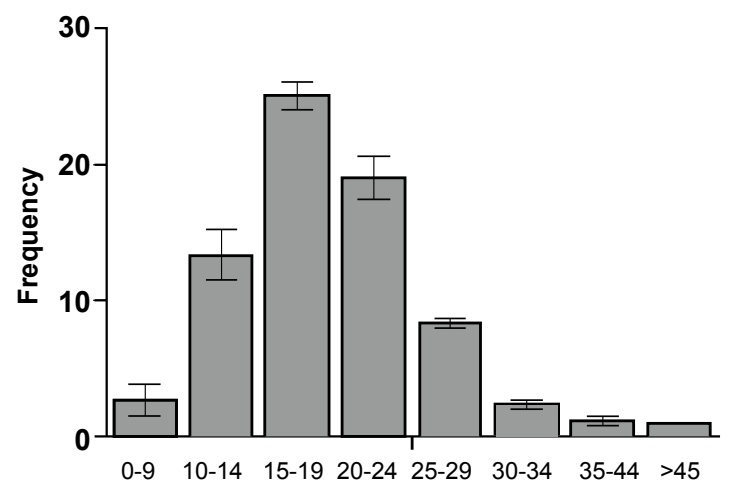

Figure 3: Tip Apex Distance measurements (in $\mathrm{mm}$ ) by frequency [error bars: s.e. of mean (3 observers, $n=3)$ ].

hospital, apart from those who have had cannulated hip screws for intracapsular fractures. Routinely bringing back to clinic all patients with a hip fracture would be unnecessary in all cases and pose a major challenge due to the high proportion with reduced mental capacity and the considerable resource implications. However, in this unit, bringing back for follow up those patients who have a high TAD would involve outpatient appointments and radiographs for a further 12 patients from the 91 trochanteric fractures in one year. This targeted approach to follow up is feasible and identifies those patients at greatest risk for re-operation.

The mean TAD for fractures treated in our centre was $19 \mathrm{~mm}$, which was better than the mean distance in the original paper of $24 \mathrm{~mm}$ [1]. This was likely due to knowledge amongst trainees and consultants of the importance intra-operatively of achieving a low TAD, conferring biomechanically more secure fixation. We achieved a similar level of inter-observer variability of $10 \%$ standard deviation, comparable to the $10 \%$ seen originally [1]. Therefore this measurement is reproducible in our experience.

We have identified the TAD as a useful, reproducible audit tool to assess the adequacy of sliding hip screw fixation in our centre. In the original study, describing calculation of the TAD to assess adequacy of lag screw placement in the femoral head, logistic regression defined a TAD value above $25 \mathrm{~mm}$ as being unsafe due to the increased risk of associated lag screw cut-out [1]. Overall, by achieving the published recommendation in 79 out of 91 sliding hip screw devices (86.9\%) here, we did not have concerns for underperformance in our unit, despite a variety of devices being used and operative treatment undertaken by both trainees and consultants. This has highlighted the need for vigilance to ensure this is maintained in practice, in addition to the 
Citation: Davies J, Mokawem M, Guy S (2012) Tip Apex Distance: a useful method to assess extra-capsular neck of femur fixation? J Trauma Treatment 1:119. doi:10.4172/2167-1222.1000119

Page 3 of 3

importance of formal arrangements for following up those patients who had a higher than expected TAD. Subsequently, a formal follow up policy was instigated in these patients who were at increased risk for lag screw cut-out.

\section{References}

1. Baumgaertner MR, Curtin SL, Lindskogg DM, Keggi JM (1995) The Value of the Tip-Apex Distance in Predicting Failure of Peritrochanteric Fractures of the Hip. J Bone Joint Surg Am 77: 1058-1064.

2. http://www.rcseng.ac.uk/news/docs/NHFD\%20\%28final\%29.pdf

3. Hsueh KK, Fang CK, Chen CM, Su YP, Wu HF, et al. (2010) Risk factors in cut-out of sliding hip screw in intertrochanteric fractures: an evaluation of 937 patients. Int Orthop 34: 1273-1276.

4. Simpson AH, Varty K, Dodd CAF (1989) Sliding hip screw: modes of failure. Injury 20: 227-231.

5. Davis TR, Sher JL, Horsman A, Simpson M, Porter BB, et al. (1990) Intertrochanteric femoral fractures: mechanical failures after internal fixation. $J$ Bone Joint Surg Br 72: 26-31.
6. Kyle RF (1994) Fractures of the Proximal Part of the Femur. J Bone Joint Surg Am 76: 924-950.

7. http://www.fractures.com/pdf/BOA-BGS-Blue-Book.pdf

8. Kyle RF, Gustilo RB, Premer RF (1979) Analysis of six hundred and twenty-two intertrochanteric hip fractures. J Bone Joint Surg Am 61: 216-221.

9. Jones $\mathrm{H}$, Johnston $\mathrm{P}$, Parker $\mathrm{M}$ (2006) Are short femoral nails superior to the sliding hip screw? A meta-analysis of 24 studies involving 3,279 fractures. Int Orthop 30: 69-78.

10. Keating JF, Robinson CM, Court-Brown CM, McQueen MM, Christie J (1993) The effects of complications after hip fracture on rehabilitation. J Bone Joint Surg $\mathrm{Br}$ 75: 976.

11. Larsson S, Friberg S, Hansson L (1990) Trochanteric fractures. Influence of reduction and implant position on impaction and complications. Clin Orthop Relat Res 259: 130-139.

12. Pervez H, Parker M, Vowler S (2004) Prediction of fixation failure after sliding hip fixation. Injury 35: 994-998. 